\title{
The Hedging Effectiveness of U.K. Stock Index Futures Contracts Using an Extended Mean Gini Approach: Evidence for the FTSE 100 and FTSE Mid250 Contracts
}

\author{
Darren Butterworth \\ Charles River Associates, London, U.K. \\ Phil Holmes \\ University of Durham, Durham, U.K.
}

\begin{abstract}
This paper provides the first investigation of the hedging effectiveness of the FTSE 100 and FTSE Mid 250 stock index futures contracts using hedge ratios generated within an extended mean Gini framework. This framework provides a robust alternative to the standard minimum variance approach, by distinguishing between different classes of risk aversion and producing hedge ratios that are consistent with the rules of stochastic dominance. The results show that the appropriate hedge ratio varies considerably with the investor's degree of risk aversion and that the EMG approach is capable of being utilized by all classes of risk averse investors, in contrast to the standard minimum variance approach. In addition, the results show strong evidence of a duration effect and support the use of the extended mean Gini approach when cross hedges are involved (JEL: G10).
\end{abstract}

Keywords: hedging; futures; mean-gini; risk aversion.

\section{Introduction}

Traditionally, the futures hedging literature has focused on the minimum variance (MV) approach of Stein (1961) and Johnson (1960), as extended by Benninga et al (1983), Lence (1995) and Rao (2000) among others. However, it is now well recognized that mean variance

\footnotetext{
${ }^{*}$ The authors gratefully acknowledge the helpful assistance of Joshua Schaefer and Natalia Chefer. We are also grateful to Antonios Antoniou, Peter Theodossiou and anonymous referees for helpful comments on an earlier draft. The usual disclaimer applies.
}

(Multinational Finance Journal, 2005, vol. 9, no. 3/4, pp. 131-160)

(C) Multinational Finance Society, a nonprofit corporation. All rights reserved. DOI: $10.17578 / 9-3 / 4-1$ 
analysis is based on rather restrictive assumptions. In response to this, the extended mean Gini (EMG) approach has been proposed as an alternative framework for analyzing hedging decisions. This approach offers greater flexibility in determining the optimal hedge ratio by allowing for differentiated risk aversion, as well as being consistent with the rules of stochastic dominance.

The use of the EMG approach to hedging is particularly relevant, given that it stresses the avoidance of downside risk. Hedging to avoid downside risk is one of the principal uses of index futures, through techniques such as portfolio insurance. The EMG approach has been used for investigating hedging effectiveness for a range of contracts including currency, commodity and US stock index futures. However, while U.K. stock index futures hedging has been investigated with respect to the MV approach (see Holmes [1995, 1996], Butterworth and Holmes [2000, 2001]), as yet there has been no investigation of hedging effectiveness for these contracts using the EMG approach. This is, perhaps, surprising given the importance of the U.K. markets in terms of the volume and value of trade and its international profile and is a major shortcoming. ${ }^{1}$ The EMG approach has the significant advantage that it can be used for all classes of risk averse investors. Thus, it is of particular use to professionally managed funds which typically have various clienteles with different degrees of risk aversion. In addition, previous work investigating hedging with U.K. stock index futures has not examined the effectiveness for hedge durations ranging from one day to one month.

This paper seeks to address some of the shortcomings by examining the hedging effectiveness of U.K. stock index futures contracts for hedge durations of one day, one week and four weeks using the EMG approach. By comparing such results with those found using the MV hedge ratio, guidance is provided to investors on the most appropriate hedging strategies to adopt, taking account of their degree of risk aversion. The remainder of this paper is structured as follows. The next

1. The London Stock Exchange (LSE) is the world's most international equities exchange in terms of the level of trading, provides Europe's largest pool of capital and is the leading provider of equity market services in the European time zone. In addition, it is linked by partnerships to international exchanges in Asia and Africa. The international significance of the LSE is attested to by the fact that the value of international listings as at 31 December 2002 was in excess of $£ 1900$ billion and the fact that the LSE lists more international companies than the NYSE and the Tokyo stock exchange combined (see LSE web page (www.londonstockexchange.com) for further details). 
section considers theoretical issues, reviews previous literature and identifies the research issues. Data and methodological issues relating to the empirical investigation are discussed in section III. Section IV reports the key empirical findings, with conclusions being drawn in section $\mathrm{V}$.

\section{Theoretical Development, Past Studies and Research Issues}

\section{A. Theoretical development}

The mean-Gini (MG) approach in finance has proved to be a useful alternative to MV modeling, since it makes no specific assumptions about the normality of the underlying probability distribution of returns, the form of the utility function or the unbiasedness of futures prices, and allows for the construction of efficient portfolios that are included in first and second order stochastic dominance portfolios. Hence, the MG coefficient provides a consistent ranking of risky alternatives whenever MV analysis fails. ${ }^{2}$ The MG coefficient (equation 1) is equal to twice the covariance between return realizations of the variable $R$ and its cumulative probability distribution $(F(R))$. As Shalit and Yitzhaki (1989) point out, this representation of the Gini mirrors the variance, apart from the fact that the cumulative probability distribution is used rather than the return itself.

$$
\Gamma=2 \operatorname{cov}(R, F(R))
$$

However, MG analysis assumes that there is only a single category of risk averse investors, while in reality there are a multitude of risk averse investors.

A framework which is capable of capturing this phenomenon while

2. The original version of the MV approach (see Johnson [1960], Stein [1961]) assumes infinite risk aversion. Subsequent work has extended the relevance to all classes of risk averse hedgers by assuming unbiased futures prices (see, for example, Benninga et al [1983], Lence [1995], Neuberger [1999] and Rao [2000]). However, such extensions require a more complicated estimation technique and the extent to which this is worthwhile has been questioned (see, for example, Baillie and Myers (1991)). More importantly, there is evidence that futures prices may be biased (see, for example, Antoniou and Holmes (1996) for the U.K.). 
retaining the desirable properties of the MG approach is the EMG family of coefficients. The MG coefficient can be subsumed into this wider family of statistics, enabling researchers to take into account the strength of the investor's degree of risk aversion and explicitly allow for the fact that risk averse investors are largely concerned only with 'down side' risk. ${ }^{3}$ The EMG coefficient, proposed by Yitzhaki (1983), can distinguish between different classes of investors by incorporating a risk aversion parameter $(v)$ which takes account of the impact of risk aversion on portfolio evaluation decisions. The EMG coefficient is defined as:

$$
\Gamma(v)=E(R)-a-\int_{a}^{b}[1-F(R)]^{v} d R
$$

$v$ is the power coefficient which reflects the degree of risk aversion, and provides the link between the EMG coefficient $(\Gamma(v))$ and the investor's attitude towards risk. For practical purposes $(\Gamma(v))$ takes the following form. ${ }^{4}$

$$
\Gamma(v)=-v \operatorname{cov}\left(R,(1-F(R))^{v-1}\right)
$$

As $v$ increases more emphasis is placed on the lower end of the distribution and attention is focused on the worst outcomes. This is intuitively appealing because a risk averse investor will attach most importance to the probability of incurring the worst realization. By assuming different values of the EMG risk aversion parameter $v$, it is possible to construct a variety of efficient portfolio sets in EMG space. While these EMG portfolios are similar in construction to MV portfolios, they have substantial advantages, in that they are encompassed in the second order stochastic dominance efficient set. ${ }^{5}$

Previous studies consider the impact which changes in the risk

3. As Hanoch and Levy (1969) argue "The identification of riskiness with variance, or with any other single measure of dispersion, is clearly unsound. There are many obvious cases, where more dispersion is desirable, if accompanied by an upward shift in the location of the distribution, or by an increasing positive asymmetry" (p. 344).

4. Note that the MG coefficient is subsumed within this class, since when $v=2$ equation 3 is equivalent to equation 1 .

5. For a discussion of the basic statistical properties of the EMG coefficient, and its relationship to stochastic dominance and portfolio risk, see Yitzhaki $(1982,1983)$ and Shalit and Yitzhaki (1984). 
aversion parameter $(v)$ have on hedging behavior. However, to date, none have attempted to provide a meaningful or intuitive interpretation of risk aversion within the EMG framework, by quantifying the significance of differences in the risk aversion parameter from the practical perspective of a risk averse investor. The impact of increasing risk aversion on portfolio return weightings is illustrated as portfolio concentration functions for a range of risk averse investors in figure 1. The curves illustrate the cumulative portfolio weight which different categories of risk averse investors attach to the worst realizations within the sample. Figure 1 illustrates the functions for a range of risk aversion parameters within the limits 1 to 200. Where the risk aversion parameter is 1 , the investor is 'risk neutral' and adopts a uniform weighting strategy, with all return realizations weighted equally. Hence, the investor is assumed to attach the same importance to the worst $50 \%$ of observations in the distribution as they do to the most favorable $50 \%$. $^{6}$ In the case of risk averse investors, the EMG approach assumes that greater attention is attached to the worst outcomes. As the risk aversion parameter $(v)$ rises, the associated portfolio concentration function becomes increasingly concave since the investor attaches increasingly greater weight to an increasingly smaller sub-sample of observations. Within the EMG framework, figure 1 shows that in the case of a: weakly risk averse investor (where $v=2$; MG approach), the investor attaches $2.1 \%$ of the total portfolio weight to the worst $1 \%$ of portfolio return realizations and $75 \%$ of the total portfolio weight to the worst $50 \%$ of portfolio return realizations ;moderately risk averse investor (where $v=10$ ), the investor attaches $9.3 \%$ of the total portfolio weight to the worst $1 \%$ of portfolio return realizations and $99 \%$ of the total portfolio weight to the worst $50 \%$ of portfolio return realizations; strongly risk averse investor (where $v=50$ ), the investor attaches $38 \%$ of the total portfolio weight to the worst $1 \%$ of portfolio return realizations and $99 \%$ of the total portfolio weight to the worst $10 \%$ of portfolio return realizations; highly risk averse investor (where $v=200$ ), the investor attaches $86 \%$ of the total portfolio weight to the worst $1 \%$ of

6. The uniform weighting strategy adopted by a risk neutral investor within an EMG framework is similar to that adopted by the investor operating within a standard MV framework, with the worst return realization being given the same portfolio weighting as the best return realization. Clearly such an approach seems at odds with investment behavior in practice. 


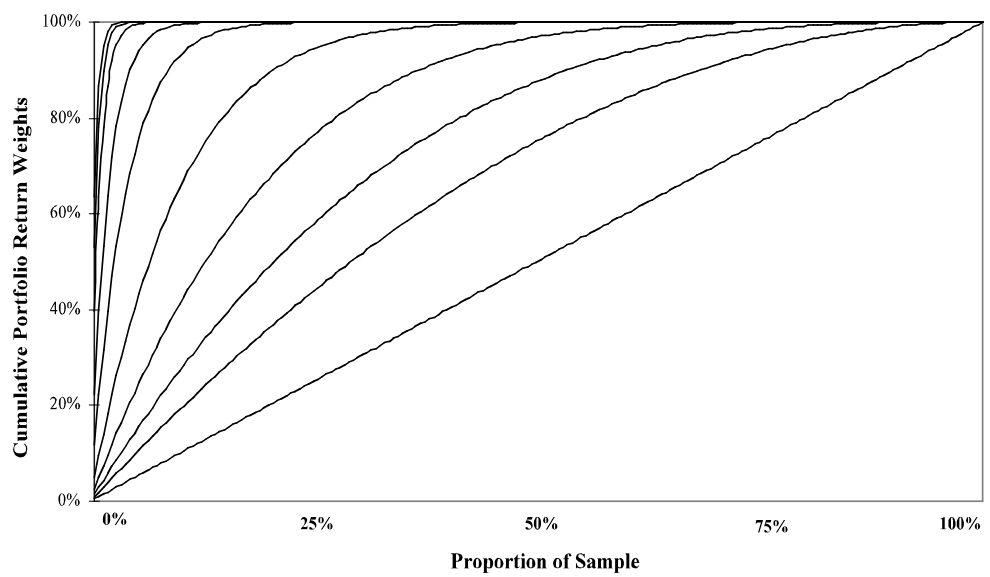

FIGURE 1.- Impact of Risk Aversion on Portfolio Return Weightings Note: The horizontal axis represents the portfolio returns which are ranked in terms of their size, with the first return in the ranked sample constituting the smallest return (most negative return), and the final return in the ranked sample constituting the largest return (most positive return). The vertical axis represents the cumulative weight attached to the various subsamples of the distribution. The portfolio concentration curves relate to risk aversion parameters ( $v$ ) equal to $1,2,3,5,10,25,50,100,150$ and 200.

portfolio return realizations and $99 \%$ of the total portfolio weight to the worst $2 \%$ of portfolio return realizations.

At the limit, as $v \rightarrow \infty$ the portfolio concentration function would converge to the north-west corner of figure 1, and the investor would attach the total portfolio weight to the worst return realization. Thus, it is evident that the EMG approach has the advantage that it can be used to determine hedging strategies for a wide range of risk averse investors.

\section{B. Literature review and research issues}

The EMG framework has been applied to the analysis of portfolio selection (Bey and Howe [1984] and Shalit and Yitzhaki [1989]), asset pricing (Carroll, Thistle and Wei [1992]) and the estimation of systematic risk (Gregory-Allen and Shalit [1999]). It has also been used for analyzing hedging. This section provides a brief review of work which used the MG and EMG approaches to investigate hedging performance for a range of futures contracts. ${ }^{7}$ Cheung, Kwan and Yip

7. For examples of where the Johnson (1960) approach has been used in the analysis of stock index futures hedging see Figlewski (1984), Junkus and Lee (1985), Graham and 
(CKY [1990]) investigate hedging effectiveness of futures and option contracts in both a MV and MG framework on a daily basis over the period September 1983 to December 1984 for five currency contracts. They find that using the MV framework results in the selection of hedge portfolios that are sometimes dominated stochastically by an alternative, in contrast to the MG approach. CKY find that futures are more effective than options at hedging in both the MG and MV frameworks, with futures reducing cash market risk by more than $55 \%$.

Hodgson and Okunev (1992) extend CKY's (1990) analysis by employing EMG coefficients. Using a basket of shares in the Australian All Ordinaries Index and All Ordinaries futures contracts for the period July 1985 to September 1986 they compare the hedging effectiveness of MV and EMG approaches. At low levels of risk aversion, hedge ratios generated by the EMG and MVHR approaches are similar, but at moderate-to-high levels of risk aversion EMG hedge ratios are significantly different from MVHRs. Daily MVHR and EMG hedge ratios are computed for a wide range of the risk aversion parameter by Kolb and Okunev (1992), for a variety of futures contracts including the S\&P 500 index contract for January - December 1989. Results are generally consistent with those of Hodgson and Okunev (1992). Kolb and Okunev (1993) compare the performance of risk minimizing and utility maximizing hedges in an EMG framework. Using monthly Cocoa prices for Ghana, Nigeria, Brazil and the Ivory Coast over the period 1952-1976, results suggest that at very low levels of risk aversion, risk minimizing and utility maximizing hedge ratios differ substantially. Indeed, the utility maximizing hedge ratio is characterized by reverse hedging (or speculative) behavior. At higher levels of risk aversion the risk minimizing and utility maximizing hedge ratios converge.

Lien and Luo (1993) use a non-parametric estimation procedure to estimate EMG hedge ratios, using weekly S\&P 500 data (1984-1988). They find the optimal hedge ratio decreases as risk aversion increases. They also find that while at low levels of risk aversion hedge ratios are stable, at higher levels of risk aversion hedge ratios are characterized by

Jennings (1987), Malliaris and Urrutia (1991), Lindahl (1992), Holmes (1996) and Butterworth and Holmes (2000). In addition, the MV approach has been used to examine hedging effectiveness for other asset types such as currency futures (see, for example, Malliaris and Urrutia [1991] and Demaskey [1997]). The mean-variance framework has also been employed to investigate international home bias in the presence of foreign exchange hedging (see Gorman and Jorgensen [2002]) and the construction of optimal portfolios of real assets (including stock indexes) and currency futures used to hedge exchange rate risk (see Adcock [2003]). 
a "widely swung step function" of the data windows.

Finally, Shalit (1995) combines normality testing of futures prices and the Hausman specification test to establish a statistical methodology for comparing hedge ratios generated within the EMG and MV frameworks. A range of metal futures contracts traded on the NY Commodity Exchange between 1977 and 1990 are examined. For all the contracts considered, Shalit finds that when contracts are normally (not normally) distributed, the probability of the two approaches exhibiting equal (unequal) hedge ratios is $70 \%(61 \%)$.

The literature review demonstrates that the EMG approach provides a robust alternative to the MV approach for investigating hedging effectiveness. By explicitly incorporating investor risk aversion into hedging decisions, it can be used to generate a broad range of hedge ratios applicable to a diverse range of investors. However, to date no examination has been undertaken of EMG hedging effectiveness with stock index futures for either cross hedges or hedges of different duration. It is of interest to determine whether the 'step function' found to characterize the relationship between the optimal hedge ratio and the level of risk aversion for a direct hedge also applies when the cash portfolio differs in composition to the index underlying the futures. Furthermore, while previous studies used different durations to investigate hedging effectiveness using the EMG approach, none have investigated the impact of changes in duration on hedging performance. In addition, and importantly, the EMG approach has not previously been applied to U.K. stock index futures. Finally, while previous tests have examined stock index futures, these tests relate to the early years of trading in index futures and there is no recent analysis of index futures during a period when the market is well established.

To address these shortcomings this paper compares the hedging performance of the FTSE 100 and FTSE Mid250 contracts using an EMG and a MV approach. Specifically; the performance of hedge ratios generated using an EMG framework is examined for the FTSE 100 and Mid250 contracts traded in the U.K. Consideration is given not only to direct hedges, but also to a range of cross hedges with cash portfolios comprising of related market indexes. This is an important issue since cross hedges have been found to be riskier than direct hedges, and it is reasonable to expect them to be more sensitive to changes in risk aversion. Furthermore, since the Mid250 contract was only introduced in 1994, it will be interesting to examine its effectiveness compared to the more established FTSE100 contract (introduced 1984). The hedging 
performance of the EMG approach is considered for hedges of different duration, since shorter duration hedges are thought to be associated with higher levels of basis risk, making them less attractive to risk averse investors. The effectiveness of the EMG hedge ratio is compared with the ex post MVHR. As the MV strategy is often used as a benchmark in the literature, insights should be provided as to whether the MV strategy warrants such a prominent position.

\section{Data And Methodology}

\section{A. Data}

Hedging effectiveness is examined for the FTSE 100 and Mid250 index futures traded on LIFFE, using cash and futures data for the period February 1994 (the introduction date of the Mid250 contract) to February 1999. The contract closest to maturity is used and is rolled-over at expiration. Cash portfolios to be hedged are represented by the following indexes: FTSE 100, FTSE Mid250, FTSE 350, FT All Share (FTALLSH) and FT Investment Trust (FTIT). ${ }^{8}$ These stock indexes capture a variety of investor activity, and it is of interest to determine whether the market risk of these indexes can be reduced by using index futures. Hedging effectiveness is investigated using daily, one week and four week duration hedges. The return series are calculated as the logarithmic price change, with 1264, 260 and 65 observations respectively. All data is obtained from Datastream.

\section{B. Methodology}

EMG and MV approaches to hedging seek to determine the hedge ratio which minimizes the risk associated with the cash portfolio, with risk measured in terms of the extended Gini coefficient and standard deviation respectively. The return on the hedged portfolio $\left(R_{h}\right)$ is expressed as:

8. The FTSE 100 index represents the largest 100 companies traded on the London Stock Exchange and the FTSE Mid250 index represents the next 250 companies (i.e. numbers 101 to 350 by market capitalization). Taken together these indexes constitute the FTSE 350 index, which covers over $90 \%$ of the U.K. equity market by market capitalization. The FT All Share encapsulates the FTSE 350 index and the FTSE SmallCap index, while the FTIT covers all of the investment trust funds trading on the London Stock Exchange. 


$$
R_{h}=R_{s}+h R_{f}
$$

$R_{s}$ is the cash portfolio return, $R_{f}$ is the futures return and $h$ is the hedge ratio. The hedge ratio which minimizes the EMG coefficient $\left(h^{E M G}\right)$ can be determined by substituting the return on the hedged portfolio (equation 4) into the EMG coefficient (equation 3):

$$
\Gamma(v)=-v \operatorname{cov}\left(R_{s}+h^{E M G} R_{f},\left(1-F\left(R_{h}\right)\right)^{v-1}\right)
$$

By expanding equation 5 with respect to the different elements of the hedged portfolio, and differentiating with respect to $h^{E M G}$, and then setting the partial derivative to zero, the global minimum EMG hedge ratio can be expressed as:

$$
h^{E M G}=\frac{-\operatorname{cov}\left(R_{f},\left(1-F\left(R_{h}\right)\right)^{v-1}\right)}{\left(\frac{\partial \operatorname{cov}\left(R_{f},\left(1-F\left(R_{h}\right)\right)^{v-1}\right)}{\partial h^{E M G}}\right)}
$$

It is clear from (6) that the hedge ratio that minimizes the EMG coefficient is a direct function of the risk aversion parameter $v$. Thus, different categories of risk averse investors are likely to have different optimal hedge ratios. ${ }^{9}$ To estimate (6) the iterative approach adopted by Hodgson and Okunev (1992) is employed. The hedge ratios that minimize the EMG coefficients are determined for each of the cash portfolios, using risk aversion parameters ranging from 2 to 200, at increments of one. ${ }^{10}$ Following Johnson (1960), the ex post MVHR is computed as follows :

9. In the case of the risk neutral investor, the risk aversion parameter is equal to 1 , hence as equation 6 collapses to zero, the return on the hedged portfolio in equation 4 equates to the return on the cash portfolio only.

10. As can be seen in figure 1, by employing risk aversion parameters within the range 2 to 200 , the impact of risk aversion on hedge generation is examined for the full gamut of risk averse investors. 


$$
h^{M V}=-\frac{\operatorname{cov}\left(R_{s}, R_{f}\right)}{\operatorname{var}\left(R_{f}\right)}
$$

Traditionally, the ex post hedge ratio $\left(h^{M V}\right)$ is estimated by regressing the cash position returns against the futures position returns (see Figlewski [1984]). More recently the limitations of the ordinary least squares (OLS) approach have been recognized and alternative methods for estimating $h^{M V}$ have been suggested. Two issues have received most attention. First, OLS assumes that the conditional covariance matrix is constant through time. In practice this may not be the case. To allow for time variation and the presence of heteroskedasticity, some authors have adopted a generalized auto-regressive heteroskedasticity (GARCH) framework for estimating the MVHR (see, for example, Holmes [1996], Myers [2000] and Dawson, Tiffin and White [2000]).

Second, a cointegrating relationship may exist between the cash and futures market price series. Failure to recognize this relationship may lead to a sub-optimal hedge. Hence, several studies have accounted for cointegration in their estimations (for example, Ghosh [1993], Holmes [1996], Lien [1996], Dawson, Tiffin and White [2000] and Sim and Zurbruegg [2001]). Given these potential problems with OLS estimation, this paper will test firstly for ARCH effects and secondly for unit roots. Where such effects are evident alternative estimating techniques will be used to take the effects into account. ${ }^{11}$

In assessing hedging effectiveness, consideration will be given to both mean returns and the degree of risk reduction. The percentage risk reduction achieved from hedging each of the cash indexes within the EMG and MV frameworks respectively is calculated as ${ }^{12}$ :

$\underset{\text { Reduction } \%}{\text { Risk }}=\left(1-\frac{\text { EMG (or S.D.) of hegded returns }}{\text { EMG (or S.D.) of unhedged returns }}\right) \times 100(8)$

11. In practice, there may well be strong grounds for believing that $\mathrm{ARCH}$ effects exist. However, given the use of return series, it may well be expected that no unit roots are evident.

12. For the purposes of comparing risk across the two approaches, Shalit (1995) points out that only where the futures prices are normally distributed will the EMG hedge ratios converge to the MV hedge ratios, and at that point the EMG coefficients are equal to the standard deviation of returns divided by a constant. 
TABLE 1. Is there evidence of ARCH effects?

\begin{tabular}{lccc}
\hline Hedged Portfolio & Daily hedges & Weekly hedges & Monthly hedges \\
\hline A. FTSE 100 Contract & & & \\
FTSE100 index & Yes & Yes & No \\
FTSE Mid250 index & Yes & Yes & No \\
FTSE 350 index & Yes & No & No \\
FTSE All Share Index & Yes & No & No \\
FTSE IT Index & Yes & No & No \\
& & & \\
B. FTSE Mid250 Contract & & & No \\
FTSE100 index & Yes & No & Yes \\
FTSE Mid250 index & Yes & Yes & No \\
FTSE 350 index & Yes & Yes & No \\
FTSE All Share Index & Yes & No & No \\
FTSE IT Index & Yes & &
\end{tabular}

Note: Based on ARCH test of residuals using the Lagrange Multiplier Test at the 5\% level.

\section{Empirical Results}

This section reports results relating to the hedging performance of the FTSE 100 and Mid250 contracts using EMG and MV approaches. However, it is necessary to first consider whether an alternative to OLS is required for estimating the MVHR. To test for ARCH effects, OLS estimation was undertaken for all hedges considered and an ARCH test of residuals was performed using the Lagrange Multiplier test. Table 1 reports findings relating to the presence of $\mathrm{ARCH}$ effects at the $5 \%$ level. The table shows evidence of ARCH effects for all daily, half of the weekly and one monthly series. Where ARCH effects exist, the MVHR is estimated using both OLS and $\operatorname{GARCH}(1,1)$. The estimated hedge ratios using the constant conditional covariance matrix and GARCH are extremely similar. In no case is the difference greater than 0.08. Similarly, differences in hedging effectiveness are extremely small, in line with previous studies (see, for example, Holmes [1996], Myers [2000] and Dawson, Tiffin and White [2000]). In all cases the MVHR estimated using OLS leads to greater risk reduction, consistent with the findings of Holmes (1996) for the U.K. ${ }^{13}$

Next, univariate tests for unit roots in the return series are

13. The results relating to GARCH estimation are available from the authors on request. 
undertaken. The tests suggest there are no unit roots, as expected ${ }^{14}$ This is consistent with the findings of, for example, Dawson, Tiffin and White (2000). It is also worth noting that Holmes (1996) finds that hedge ratios estimated by OLS provide greater risk reduction than error correction mechanism based estimations for the U.K.

In the light of the above and the current paper's focus on the EMG, the MVHRs reported are those estimated by OLS. ${ }^{15}$ Results for daily, one week and four week hedges are reported in tables 2, 3 and 4 respectively, and depicted in figure 2. All tables are organized in the same way, consisting of two panels; panel A reports the summary statistics for hedges using the FTSE 100 contract, and panel B reports the summary statistics for hedges using the Mid250 contract. Within each panel results are reported for each of the cash portfolios. The size of the hedge ratio, the level of risk reduction, the mean returns and a relative returns statistic are reported. ${ }^{1617}$ Given the voluminous results, those relating to only a selection of risk aversion parameters are presented. ${ }^{18}$

Results reported in table 2 panel A relate to hedging with the FTSE 100 contract using daily duration hedges. For the direct hedge, at low levels of risk aversion ( $v=2$ to $v=10$ ), the EMG and MV hedge ratios are similar, $0.83-0.84$ and 0.83 respectively. At higher levels of risk aversion $(v=200)$ the EMG hedge ratio deviates markedly from the MVHR, with values of 0.73 and 0.83 respectively Focusing on the risk-return relationship, the MV approach removes $70 \%$ of the risk of the underlying cash index, compared to $70.9 \%$ for the MG strategy

14. Details of the unit root tests are available from the authors on request.

15. It should also be noted that ARCH effects or cointegration will impact on diagnostic statistics, but that the OLS estimate remains consistent in the presence of these effects. Given that tests using diagnostic statistics are not undertaken here, the OLS estimates can be used with confidence.

16. All mean returns reported in the tables and text have been annualized to allow a more convenient comparison between hedges of different duration.

17. The relative returns statistic compares mean returns achieved using the EMG approach to those achieved using the MV approach. It measures the percentage reduction or increase of the MV hedged returns achieved by the EMG hedge.

18. The EMG hedging results relating to the other risk aversion parameters are available from the authors on request. 


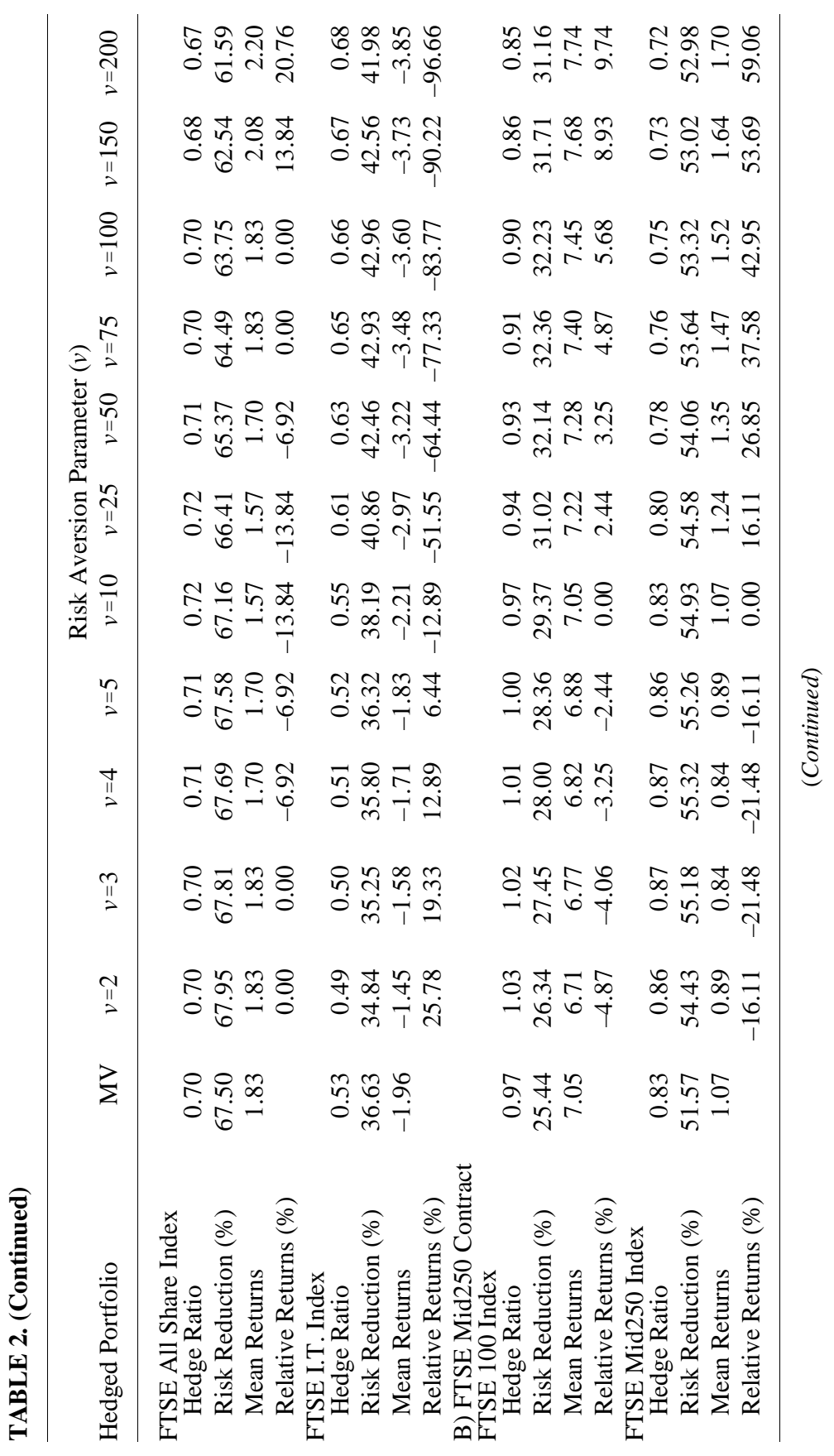




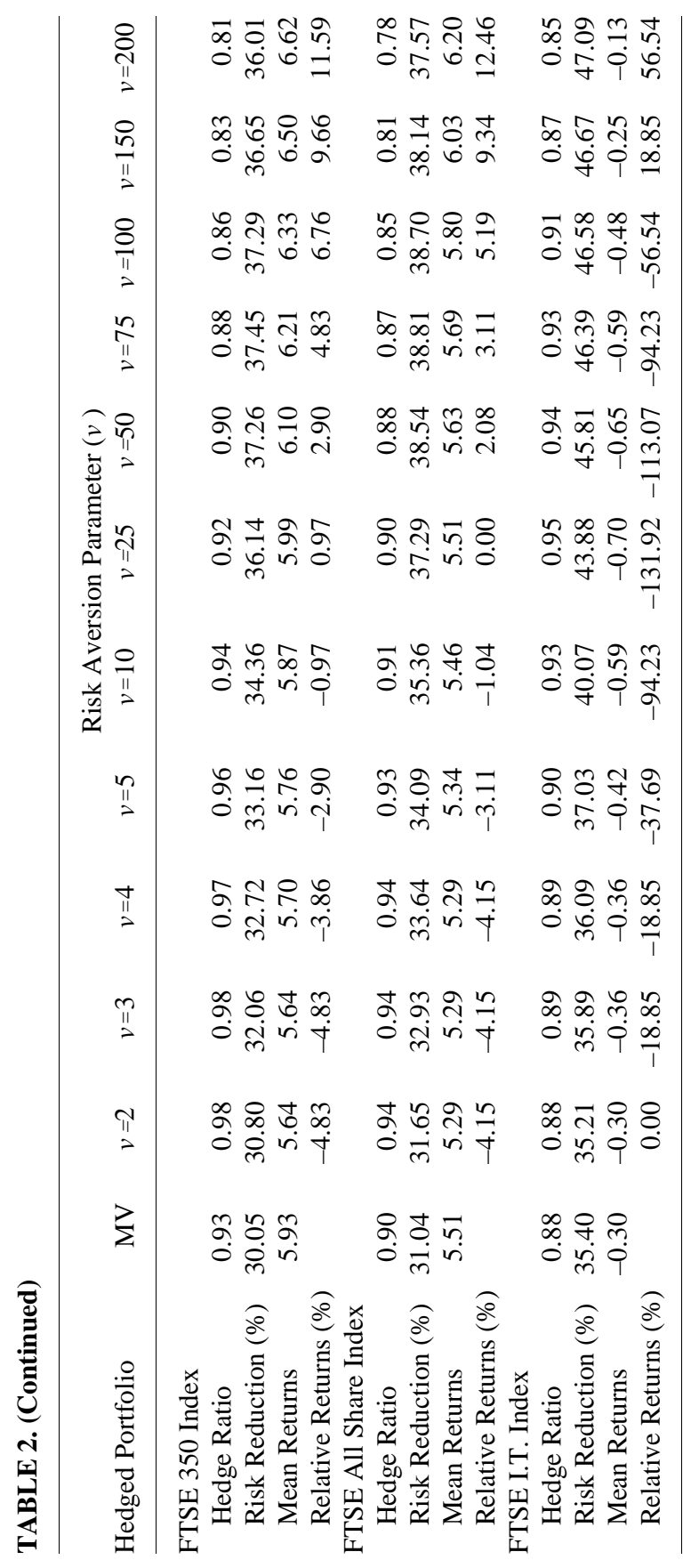


when $v=2 .{ }^{19}$ However, the MG strategy is associated with hedged returns 6\% lower than the MV approach. As $v$ increases, risk reduction falls and mean returns rise. For values of $v>10$ mean returns are greater than for the MV hedge. Indeed, for a highly risk averse investor ( $v$ $=200$ ), the EMG strategy provides a mean return 59.5\% higher than the MV strategy, while eliminating $62 \%$ of risk.

For the direct hedge using the Mid250 futures (table 2, panel B), risk reduction is significant within both frameworks. However, the levels are substantially less than those achieved for the FTSE 100. The lower levels of risk reduction (typically within the range 10-20\%) are consistent across both hedging strategies and all values of $v$. This difference is probably due to the Mid250 contract being thinly traded compared to the FTSE 100, and the Mid250 has a large number of constituents which are infrequently traded. This results in greater basis risk for the Mid250 futures. Hence, the release of news of a pervasive systematic nature may be incorporated more rapidly into the FTSE 100 cash and futures prices, than in the Mid250 sector of the market.

Furthermore, the Mid250 direct hedge is characterized by a similar relationship as the FTSE100, with MVHR and EMG hedge ratios being similar at low levels of risk aversion, but considerably different at higher levels. However, there is some divergence even for low values of $v$ for the Mid250 contract. Therefore, while the MV approach is more appropriate for the case of weakly risk averse investors, there are some differences at low levels of $v$ and the MV strategy is clearly inappropriate for highly risk averse investors, especially those wishing to undertake a short duration hedge.

Considering cross hedges, table 2, panel A reports the daily results associated with the FTSE 100 contract. While the risk reduction is not as great as the direct hedge it is still considerable, with similar risk reduction achieved for both weakly and highly risk averse investors using the EMG. For the Mid250, FTSE 350, FTALLSH and FTIT indexes the risk reduction achieved by a weakly risk averse investor: $v$ $=2$ (highly risk averse investor: $(v=200)$, is $26.3 \%(28.4 \%), 68.9 \%$ $(62.1 \%), 67.9 \%(61.6 \%)$ and $34.8 \%(42.0 \%)$ respectively. For the Mid250 contract, table 2, panel B shows daily cross hedging results for

19. While the risk reduction potential of the MV and EMG approaches are not strictly comparable, given that the reduction in the dispersion of returns is measured by changes in the standard deviation and the EMG coefficient respectively, nonetheless considering the differences provides useful insights into the differences in hedging behavior within the two approaches. 
A. FTSE 100 Contract

FTSE 100 Index

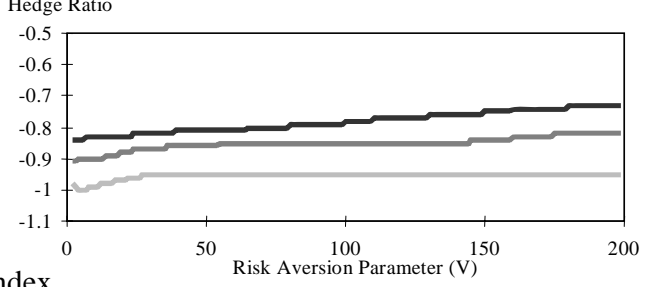

FTSE Mid250 Index

$50 \stackrel{100}{150}$

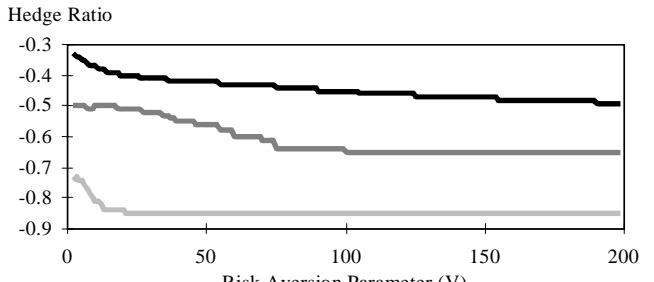

FTSE 350 Index

Risk Aversion Parameter (V)

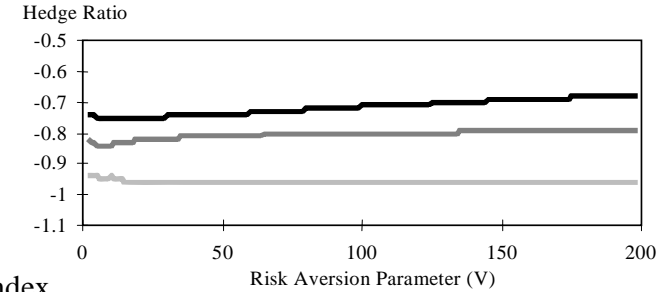

FT All Share Index

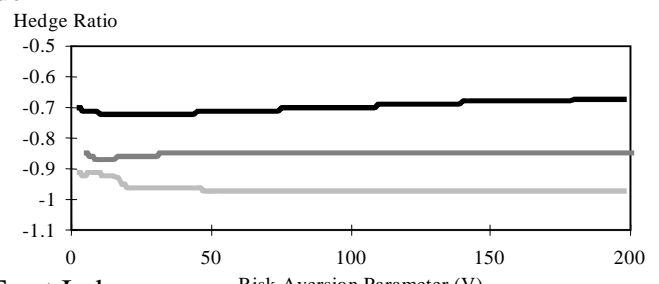

FT Investment Trust Index

Risk Aversion Parameter (V)

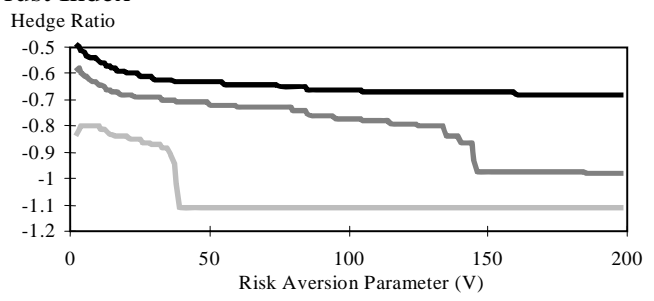

FIGURE 2-

Extended Mean Gini Hedge Ratios: FTSE 100 and FTSE Mid250 Contracts

(Continued) 


\section{B. FTSE Mid250 Contract}

FTSE 100 Index

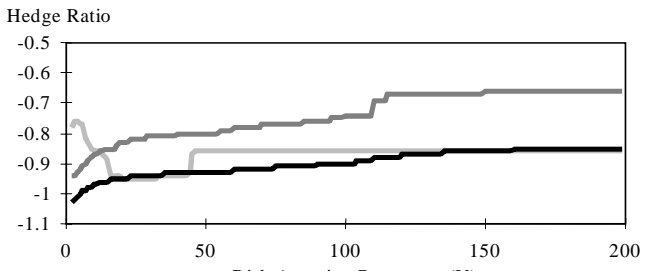

FTSE Mid250 Index

Risk Aversion Parameter (V)

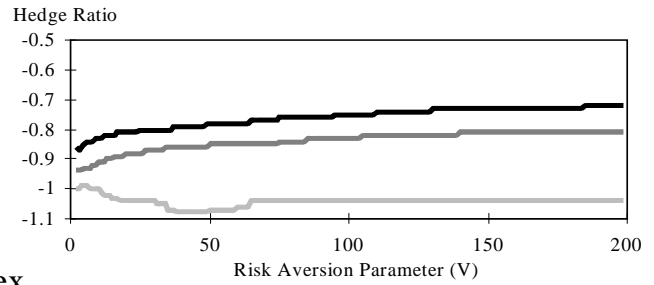

FTSE 350 Index

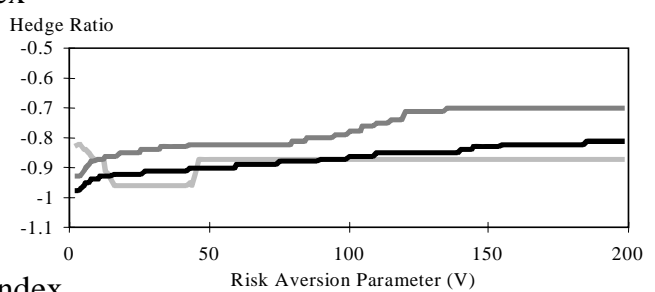

FT All Share Index

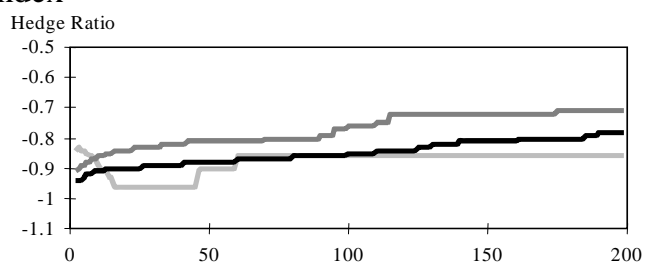

FT Investment Trust Index

Risk Aversion Parameter (V)

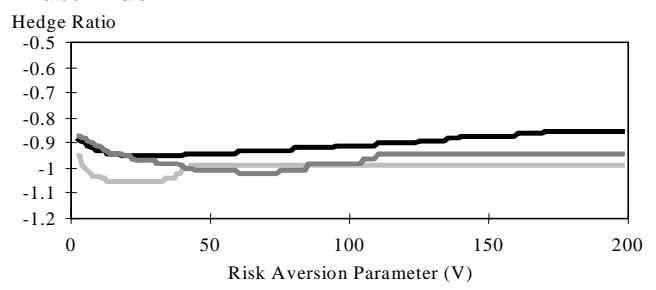

FIGURE 2-(Continued)

Note: The plots show EMG hedge ratios as a function of the risk aversion parameters for hedges of four week, one week and daily duration. Where the daily series is represented by the bold black function, the one week series is represented by the dark grey function and the four week series is represented by the light grey function. 
the FTSE 100, FTSE 350, FTALLSH and FTIT indexes. It is apparent that the FTSE 100 contract produces the most effective results for those indexes dominated by large capitalization stocks (FTSE 100, FTSE 350 and FTALLSH) in terms of risk reduction. In contrast, the Mid250 contract provides the most effective hedges for those indexes dominated by smaller capitalization stocks (Mid250 and FTIT). This suggests that while the more recently introduced Mid250 contract is not as effective as the more established FTSE 100 contract at direct hedging on a daily basis, it nonetheless, performs a useful function in terms of being a more effective hedging instrument for some portfolios. This finding holds for both the MV and EMG approaches. Again, the results show differences in the hedge ratios estimated using the MV and EMG approaches.

Figure 2 illustrates how the EMG hedge ratio changes for different levels of $v$. It is clear that the daily hedge ratio series is characterized by a 'step function', whereby all hedged portfolios are associated with a number of distinct ratios. As Hodgson and Okunev (1992) point out, the practical implication of this is that it is not always necessary to precisely measure an investor's degree of risk aversion to determine which hedge ratio most appropriately meets their preferences. Rather, the investor has only to choose between a range of different risk categories. Therefore, the EMG approach offers a range of hedge ratios which suit the requirements of different categories of risk averse investors.

The article now considers the issue of a duration effect. Examining results for the FTSE 100 contract in panel A of tables 2, 3 and 4, it is possible to see the impact on hedging effectiveness when duration shifts from hedges of one day, to one week and four weeks. For the direct FTSE 100 hedge, effectiveness improves for all types of risk averse investor as duration rises. For example, for the weakly risk averse investor: $v=2$ (highly risk averse investor: $v=200$ ), risk reduction increases from $70.9 \%(62.0 \%)$, to $79.3 \%$ (71.9\%) to $83.3 \%$ (89.2\%) for daily, weekly and four weekly hedges. Longer hedges relating to the Mid250 contract are also more effective than shorter hedges for allcategories of risk averse investors. The increase for the Mid250 is more marked. For some values of $v$ hedging effectiveness is greater for the Mid250 than for the FTSE 100 contract for four week hedges. Even so, the benefits of greater risk reduction achieved through employing longer hedges, result in a decline in the mean returns in the case of both the FTSE 100 and Mid250 contracts. 
It is also seen that for direct hedges consisting of the FTSE 100 and Mid250 indexes, as duration increases, so does the size of the hedge ratio. This reflects the fact that basis risk is lower for longer hedges. Figures 2(ai) and 2(bii) show that not only do hedge ratios for longer durations increase, but they are also characterized by greater stability. This is consistent with the theoretical underpinnings of the EMG coefficient, since as risk aversion increases, the EMG hedge ratio is being calculated with respect to an increasingly smaller subset of observations. Therefore, the potential for the hedge ratio to change is severely constrained.

There is also evidence of a duration effect for the various cross hedges involving the FTSE 100 and Mid250 contracts. Comparing daily and four week hedges in tables 2 and 4, it can be seen from panels A and B, that for the FTSE 100 and Mid250 contract, longer hedges reduce risk by up to about $20 \%$ for all categories of risk averse investors using the EMG approach. It is also evident from figure 2, that cross hedges associated with the FTSE 100 contract are less sensitive to changes in risk aversion than are those associated with the Mid250. In fact the hedge ratio series associated with the FTSE 100 contract (in figure 2a) are smoother and more uniform than those for the cross hedges associated with the Mid250 contract (figure 2b). For the hedge ratio series characterized by considerable variation, (for example, between the FTSE 100 contract and FTIT index, and the Mid250 contract and the FTSE 100 index), it is reasonable to hypothesize that unhedgeable cross hedging risk may contribute to this instability. This holds because the FTSE 100 and Mid250 contracts mirror the performance of specific sectors of the market, and are likely to be less responsive to shocks which occur in areas of the market which are not specific to their underlying index. For the Mid250 contract this is likely to be exacerbated by thin trading, especially for shorter duration hedges.

Finally, it is again worth noting the differences in hedge ratios estimated by the MV and EMG approaches even for four week hedges and relatively low levels of $v$. For example, consider hedging the FTIT index with the FTSE100 (Mid250) contract. For four week hedges the MVHR is 0.91 (1.00) compared to $0.81(0.95)$ for $v=3$. Indeed the EMG hedge ratio varies from $0.80(0.95)$ to $1.10(1.05)$ depending on $v$. 


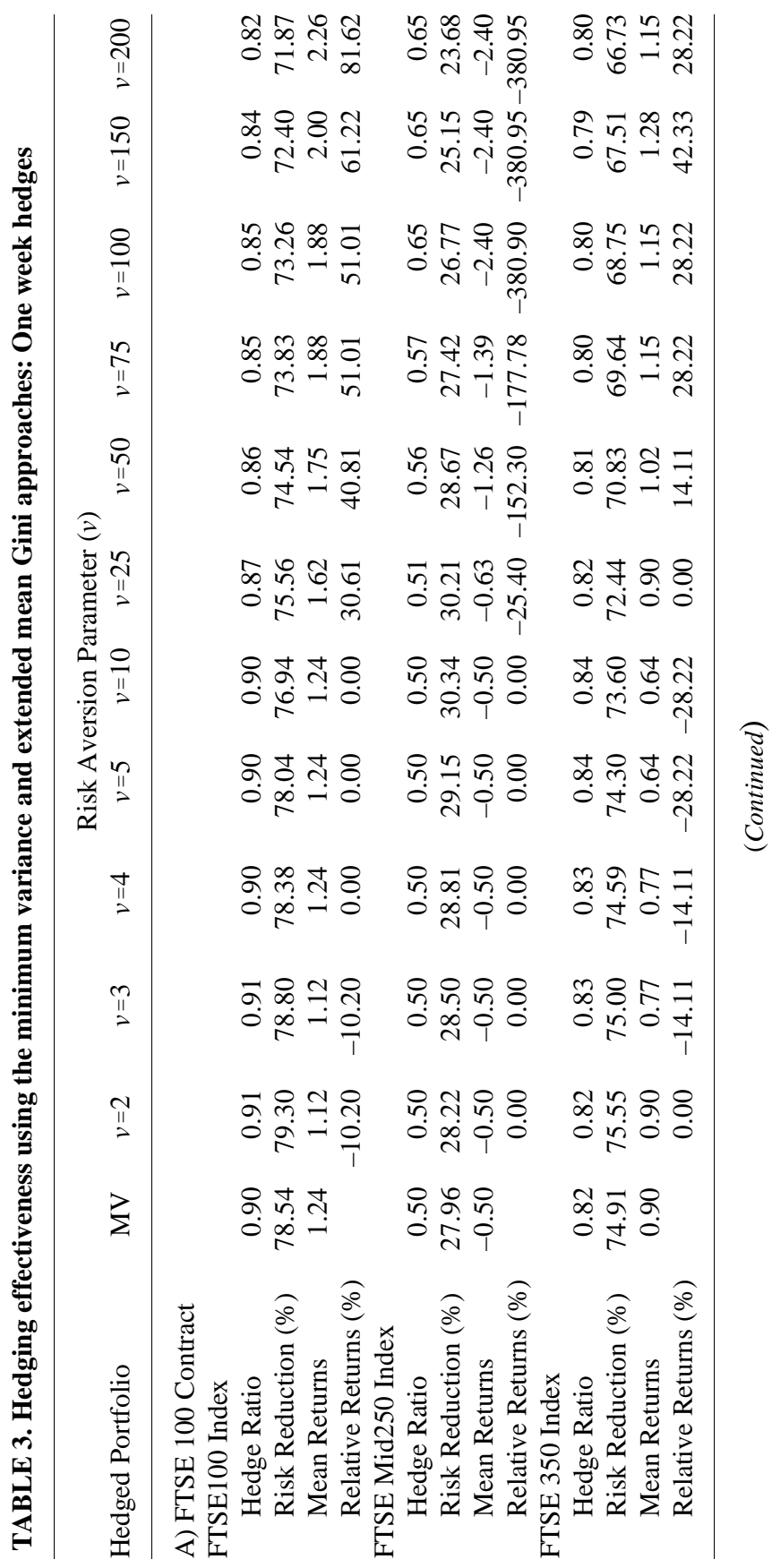


Hedging Effectiveness, Extended Mean Gini

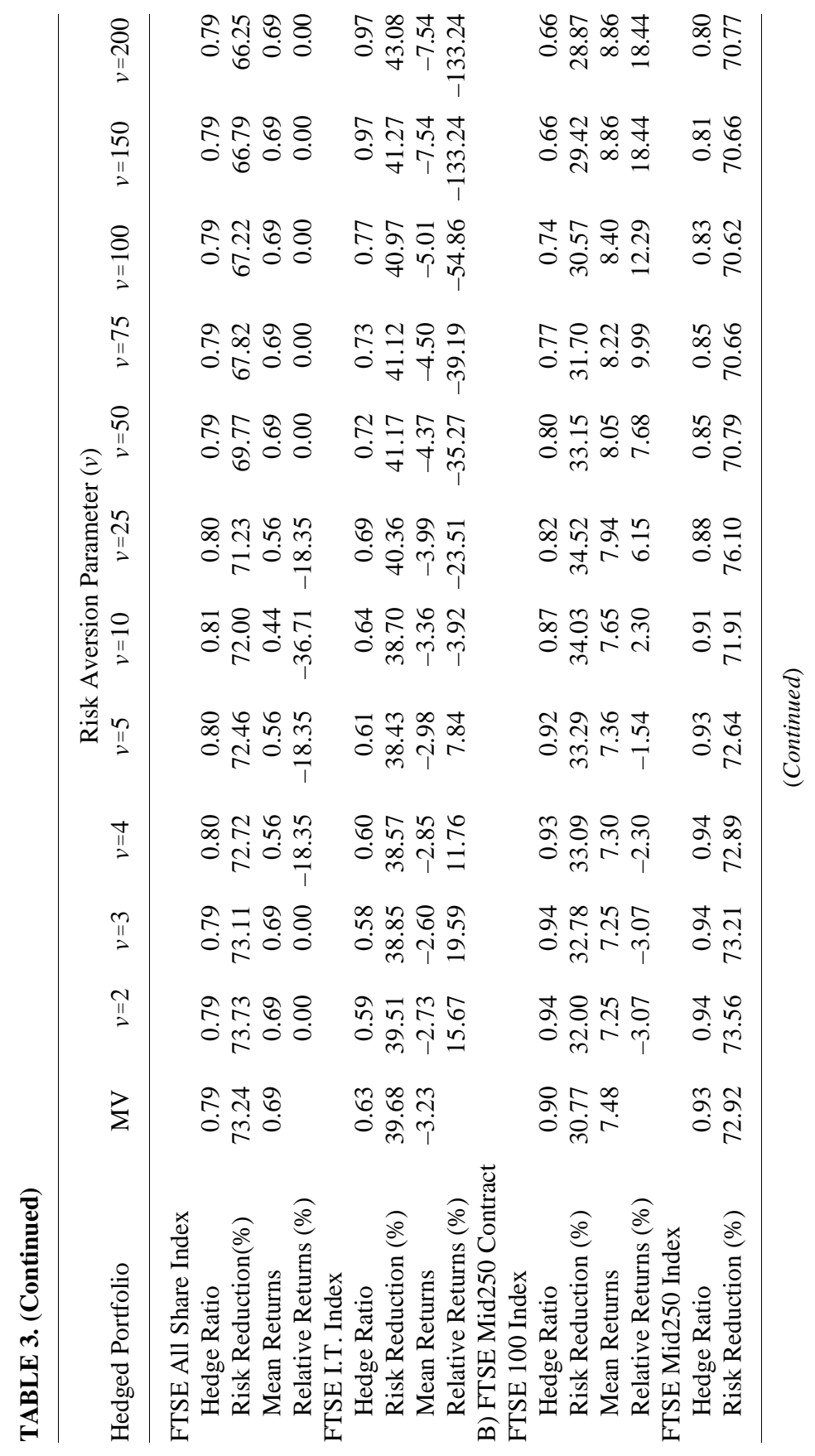


Hedging Effectiveness, Extended Mean Gini

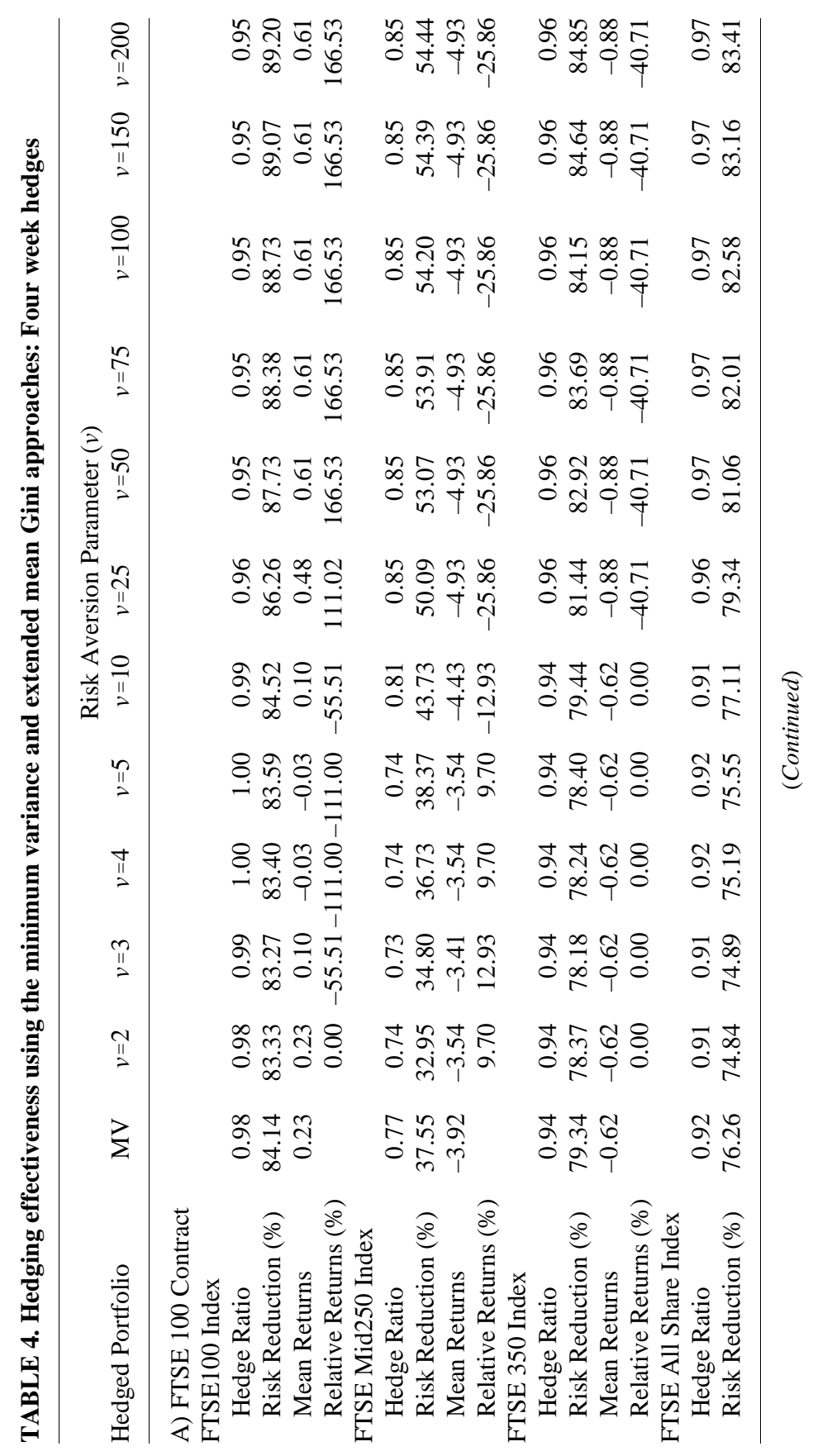




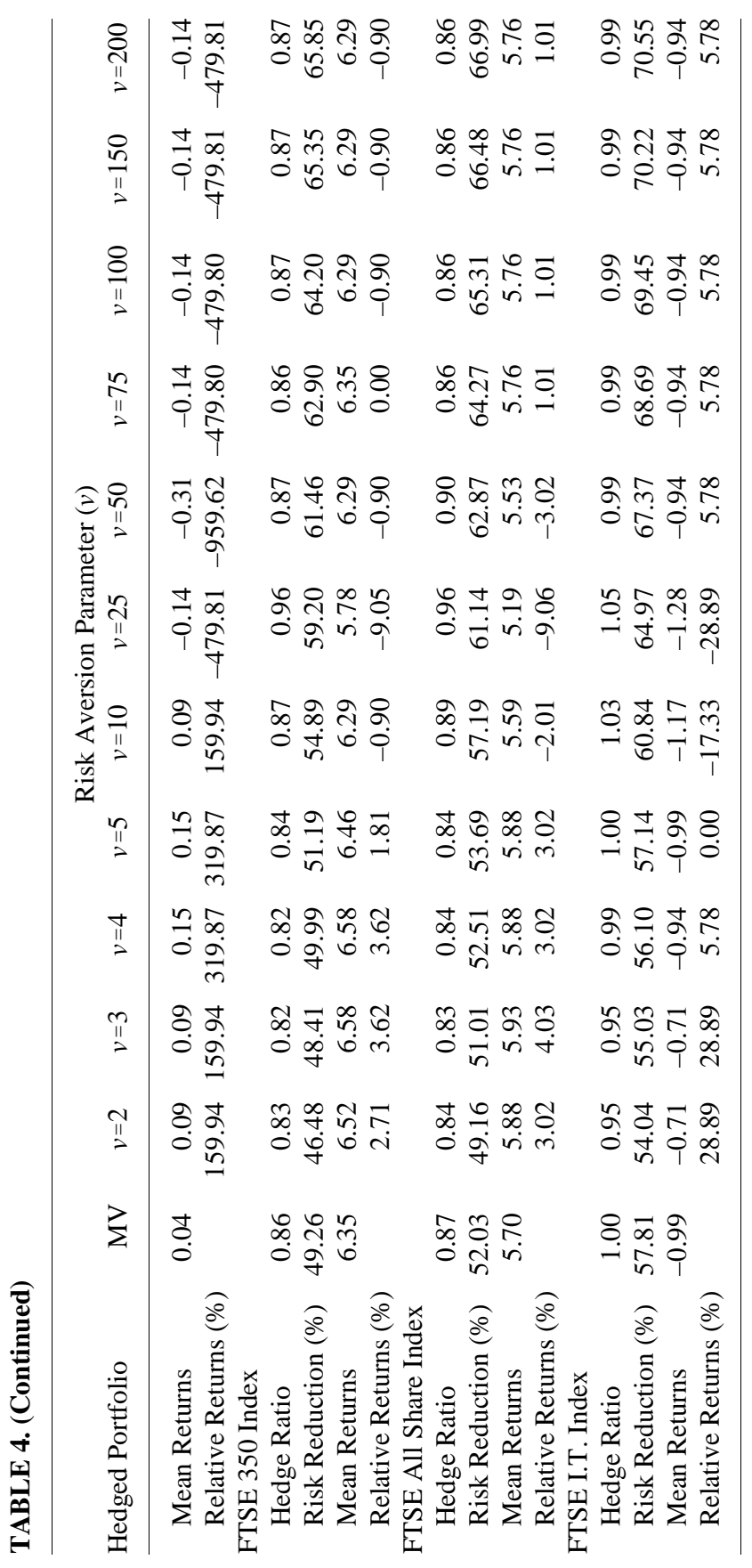




\section{Conclusions}

This paper examines hedging and cross-hedging effectiveness of the FTSE 100 and Mid250 contracts within EMG and MV frameworks with respect to a range of stock indexes. The EMG approach is consistent with the rules of stochastic dominance and offers flexibility in determining the optimal hedge ratio by allowing for differentiated risk aversion. It thereby captures the observed diversity in hedging objectives and behavior. Overall results show that the traditional reliance on the MVHR for generating the optimal hedge ratio may be misguided, even when using more advanced econometric techniques such as GARCH. The results indicate that while the MVHR is generally applicable for weakly risk averse investors, it is inappropriate for more highly risk averse investors who are increasingly concerned about their exposure to downside risk. As such, while the MVHR may be suitable for some investors, it is not for others. In contrast, the EMG approach is applicable to all classes of risk averse investors.

The results also confirm that the EMG hedging approach is useful for cross hedging. The FTSE 100 contract produces the most effective hedges for indexes dominated by large capitalization stocks, and the Mid250 the most effective for indexes dominated by smaller capitalization stocks. It is apparent that using the EMG approach to generate cross hedges, produces hedge ratios characterized by greater variability. Furthermore, results show that hedge ratios generated by the EMG approach are associated with a strong duration effect, with longer duration hedges achieving greater risk reduction for all categories of risk averse investors. However, this is at the cost of a decline in mean returns. In conclusion, it is evident from the results presented here that the EMG approach to hedging is more generally applicable than is the MV approach, which has been widely used in the literature. The results give clear guidance as to how investors can devise hedging strategies on the basis of the portfolio to be hedged, the degree of risk aversion and the duration of the hedge.

\section{References}

Adcock, C.J. 2003. An empirical study of portfolio selection for optimally hedged portfolios. Multinational Finance Journal, 7: 83-106.

Antoniou, A., Holmes, P. 1996. Futures market efficiency, the unbiasedness hypothesis and variance-bounds tests: The case of the FTSE-100 futures contract. Bulletin of Economic Research, 48: 115-128. 
Baillie, R.T., Myers, R.J. 1991. Bivariate GARCH estimation of the optimal commodity futures hedge. Journal of Applied Econometrics, 6: 109-124.

Benninga, S.; Eldor, R.; Zilcha, I. 1983. Optimal hedging in the futures market under price uncertainty. Economics Letters, 13: 141-145.

Bey, R., Howe K. 1984. Gini mean difference and portfolio selection: An empirical evaluation. Journal of Financial and Quantitative Analysis, 19: 329-338.

Butterworth, D., Holmes P. 2000. Ex ante hedging effectiveness of stock index futures contracts: Evidence for the FTSE 100 and FTSE Mid250 contracts. European Financial Management, 6: 441-459.

Butterworth, D., Holmes P. 2001. The hedging effectiveness of stock index futures: Evidence for the FTSE 100 and FTSE Mid250 indexes. Applied Financial Economics, 11: 57-68.

Carroll, C.; Thistle P.; Wei K. 1992. The robustness of risk-return nonlinearities to the normality assumption. Journal of Financial and Quantitative Analysis, 27: 419-435.

Cheung, C.; Kwan C.; Yip P. 1990. The hedging effectiveness of options and futures: A mean gini approach. Journal of Futures Markets, 10: 61-73.

Dawson, P.; Tiffin, A.L.; White, B. 2000. Optimal hedging ratios for wheat and barley at the LIFFE: A GARCH approach. Journal of Agricultural Economics, 51: 147-161.

Demaskey, A.L. 1997. Single and multiple portfolio cross-hedging with currency futures. Multinational Finance Journal, 1: 23-46.

Figlewski, S. 1984. Hedging performance and basis risk in stock index futures. Journal of Finance, 39: 657-669.

Ghosh, A. 1993. Hedging with stock index futures: Estimation and forecasting with error correction model. Journal of Futures Markets, 13: 743-752.

Gorman, L.R., Jorgensen, B.N. 2002. Domestic versus international portfolio selection: A statistical examination of the home bias. Multinational Finance Journal, 6: 131-166.

Graham, D., Jennings, R. 1987. Systematic risk, dividend yield and the hedging performance of stock index futures. Journal of Futures Markets, 7: 1-13.

Gregory-Allen, R., Shalit, H. 1999. The estimation of systematic risk aversion under differentiated risk aversion: A mean-extended gini approach. Review of Quantitative Finance and Accounting, 12: 135-157.

Hanoch, G., Levy H. 1969. The efficiency analysis of choices involving risk. Review of Economic Studies, 36: 335-346.

Hodgson, A., Okunev J. 1992. An alternative approach for determining hedge ratios for futures contracts. Journal of Business, Finance and Accounting, 19: 211-224.

Holmes, P. 1995. Ex ante hedge ratios and the hedging effectiveness of the FTSE-100 stock index futures contract. Applied Economics Letters, 2: 56-59. 
Holmes, P. 1996. Stock index futures hedging: Hedge ratio estimation, duration effects, expiration effects and hedge ratio stability. Journal of Business, Finance and Accounting, 23: 63-77.

Johnson, L. 1960. The theory of hedging and speculation in commodity futures markets. Review of Economic Studies, 27: 139-151.

Junkus, J.C., Lee, C.F. 1985. Use of three stock index futures in hedging decisions. Journal of Futures Markets, 5: 201-222.

Kolb, R., Okunev J. 1992. An empirical evaluation of the extended gini coefficient for futures contracts. Journal of Futures Markets, 12: 177-186.

Kolb, R., Okunev J. 1993. Utility maximizing hedge ratios in the extended mean gini framework. Journal of Futures Markets, 13: 597-609.

Lence, S.H. 1995. On the optimal hedge under unbiased futures prices. Economics Letters, 47: 385-388.

Lien, D. 1996. The effect of the cointegration relationship on futures hedging: A note. Journal of Futures Markets, 16: 773-780.

Lien, D., Luo X. 1993. Estimating the extended mean-gini coefficient for futures hedging. Journal of Futures Markets, 13: 665-676.

Lindahl, M. 1992. Minimum variance hedge ratios for stock index futures: duration and expiration effects. Journal of Futures Markets, 12: 33-53.

Malliaris, A.G., Urrutia, J. 1991. Tests of the random walk of hedge ratios and measures of hedging effectiveness for stock indexes and foreign currencies. Journal of Futures Markets, 11: 55-68.

Myers, R. 2000. Estimating the time varying optimal hedge ratio on futures markets. Journal of Futures Markets, 11: 39-53.

Neuberger, A. 1999. Hedging long-term exposures with multiple short-term futures contracts. Review of Financial Studies, 12: 429-459.

Rao, V.K. 2000. Preference-free optimal hedging using futures. Economics Letters, 66: 223-228.

Shalit, H. 1995. Mean gini hedging in futures markets. Journal of Futures Markets, 15: 617-635.

Shalit, H., Yitzhaki S. 1984. Mean gini portfolio theory and the pricing of assets. Journal of Finance, 39: 1449-1468.

Shalit, H., Yitzhaki S. 1989. Evaluating the mean gini approach to portfolio selection. International Journal of Finance, 1: 15-31.

Sim A., Zurbruegg, R. 2001. Optimal hedge ratios and alternative hedging strategies in the presence of cointegrated time-varying risks. European Journal of Finance, 7: 269-283.

Stein, J. 1961. The simultaneous determination of spot and futures prices.American Economic Review, 51: 1012-1025.

Yitzhaki, S. 1982. Stochastic dominance, mean variance and gini mean difference. American Economic Review, 72: 178-185.

Yitzhaki, S. 1983. On an extension of the gini inequality index. International Economic Review, 24: 617-628. 